Klaus Schreiner, Rituale, Zeichen, Bilder. Formen und Funktionen symbolischer Kommunikation im Mittelalter Köln, Weimar, Wien : Böhlau (Norm und Struktur 40), 2011, 342 p., 49,90€

Pierre Monnet

\title{
CpenEdition
}

Journals

Édition électronique

URL : http://journals.openedition.org/ifha/7520

DOI : 10.4000/ifha.7520

ISSN : 2198-8943

Éditeur

IFRA - Institut franco-allemand (sciences historiques et sociales)

Référence électronique

Pierre Monnet, « Klaus Schreiner, Rituale, Zeichen, Bilder. Formen und Funktionen symbolischer Kommunikation im Mittelalter », Revue de l'IFHA [En ligne], Date de recension, mis en ligne le 13 décembre 2013, consulté le 22 septembre 2020. URL : http://journals.openedition.org/ifha/7520 DOI : https://doi.org/10.4000/ifha.7520

Ce document a été généré automatiquement le 22 septembre 2020.

(CIFHA 


\section{Klaus Schreiner, Rituale, Zeichen, Bilder. Formen und Funktionen symbolischer Kommunikation im Mittelalter}

Köln, Weimar, Wien : Böhlau (Norm und Struktur 40), 2011, 342 p., 49,90€

Pierre Monnet

Cet ouvrage rassemble six des articles les plus marquants du médiéviste de Bielefeld parus entre 1996 et 2004. C'est la ligne d'une histoire anthropologique et symbolique du politique au Moyen Âge qui a guidé le choix des éditeurs du volume, Ulrich Meier (Bielefeld), Gabriela Signori (Constance) et Gerd Schwerhoff (Dresde), tous trois disciples et continuateurs de la pensée de leur maître. Qualifié naguère par Percy Ernst Schramm de " temps des signes ", le Moyen Âge se signale par sa capacité à produire et à remployer un langage symbolique, gestuel, rituel et visuel que les médiévistes ont désormais appris à décrypter dans ses singularité et étrangeté. Parmi eux, Klaus Schreiner, connu par ailleurs pour ses travaux classiques sur le culte et les images de Marie au Moyen Âge, s'est employé à installer drapeaux, croix, bustes, baiser, lavement des pieds ou lettres de l'alphabet... comme autant de supports de signification aussi parlants que l'écrit ou l'oral. La lecture de ces six contributions, comme celle d'ailleurs des nombreux autres travaux du récipiendaire dont la liste exhaustive est fournie en fin de volume, suggère que cette histoire symbolique ne reste pas enfermée dans une herméneutique close des signes mais ne prend son sens que dans l'inscription sociopolitique et socioculturelle de la création et de l'usage des gestes, rituels et symboles dans une configuration donnée. La méthode apparaît avec clarté et efficacité dans le dernier article consacré à l'usage des livres et des initiales manuscrites dans les rituels de consécration et d'ordination conduits par l'Eglise médiévale. En effet, le livre ne fait pas que reproduire la parole sainte mais accompagne la relation des ordinations de prophètes ou d'apôtres d'initiales et d'images dont l'emploi rituel et gestuel est intégré dans le déroulement même de la liturgie. C'est ainsi que des évêques sont ordonnés et consacrés le livre saint posé sur la nuque et ouvert à l'endroit même où 
l'enluminure montre une scène d'ordination. Dès lors c'est toute la signification d'une grammaire à la fois visuelle, gestuelle, orale et écrite du livre tantôt ouvert, tantôt fermé, tantôt posé sur le cou, ou sur la tête ou sur les épaules lors de cette impositio evangelii qui est ici livrée. C'est une histoire de longue durée qui est ici racontée puisqu'elle ne s'achève pas seulement avec l'intronisation du livre saint lors des conciles ou avec l'emploi des lettres de l'alphabet sur le sol lors des consécrations d'église mais se déploie bien davantage dans une séquence symbolique qui ne change réellement de sens qu'à partir du moment où le livre imprimé fait sortir la lettre du geste créateur du clerc et du copiste. La méthode, qui croise les temps, les espaces et les supports pour sentir et décrire l'historicité des signes médiévaux vaut également pour les autres exemples retenus dans le présent volume. Ainsi en va-t-il pour les signes de la victoire appelés et mobilisés lors des batailles : croix bien entendu mais aussi fanions consacrés et bénis ou bien reliques montrées et transportées sur le champ de bataille. Ces signes (Hoc signo tuetur pius. Hoc signo vincitur inimicus) envoyés ou mobilisés pour la promesse d'une victoire sainte, depuis les matrices de l'auxilium Dei procuré à Constantin et à Clovis entre autres, permettent ainsi à $\mathrm{K}$. Schreiner de relire à nouveaux frais la symbolique guerrière et sacrée dans des contextes changeants, ceux des guerres « intestines " à l'Occident chrétien comme ceux de la croisade et ensuite de la lutte contre les Turcs. Mais ce n'est pas une histoire linéaire ou univoque que celle qui mobilise le référent du pro patria mori jusqu'à la résurgence contemporaine du «Gott mit uns » en plein XXe siècle : au contraire, et dès le Moyen Âge, nombreux furent les théologiens à s'interroger sur la légitimité d'une mobilisation des signes saints pour tuer au nom de Dieu, jusqu'aux condamnations sans appel que prononcèrent les humanistes envers ce détournement, cette instrumentalisation abusive de la sacralité pout occire son prochain. Les signes et les symboles, c'est là le propre de leur nature, ne sont jamais simples ni catégoriquement explicites puisqu'ils unissent par définition deux ordres de réalité et de sens dont l'ajustement fait précisément la plasticité et l'historicité. Cette approche en nuance, respectueuse de la richesse et de la combinatoire symboliques, caractérise les autres contributions du volume, qu'il s'agisse des rituels pacifiques du baiser ou de l'amende honorable nus pieds (un motif commun au Christ, aux moines, aux pénitents et aux pèlerins), dont la déritualisation à partir du $\mathrm{XIII}^{\mathrm{e}}$ siècle accompagne la monétarisation des peines, des sacrements, des indulgences et des pardons; ou bien qu'il s'agisse des images et usages du sein et du lait de Marie, dont une partie servira d'ailleurs à nourrir le discours antijuif. C'est l'histoire évolutive de cette attribution de sens, attentive aux détails des textes et des images, qui permet à K. Schreiner de se garder des péchés mortels de l'anachronicité, de l'anhistoricité et de l'automaticité de l'analyse des rituels. Ce dossier de six articles riches et fondateurs rend parfaitement justice de cette méthode et de cette posture.

\section{INDEX}

Index chronologique : Mittelalter

Thèmes : Sozialgeschichte 
AUTEUR

PIERRE MONNET

IFHA, Francfort-sur-le-Main et EHESS, Paris 